\title{
Nwomu: Hand-Made Embroidery Technique in Asanteland
}

\author{
Emmanuel Kodwo Amissah \\ University of Education, \\ Winneba, Ghana
}

\author{
Bernard Asumeng Amoako \\ SDA Senior High School, \\ Koforidua, Ghana
}

\author{
Osuanyi Quaicoo Essel \\ University of Education, \\ Winneba, Ghana
}

\begin{abstract}
The study sought to investigate the historical background of the traditional hand-made embroidery technique, the production process, and its changing trends amongst the Asantes of Ghana. Interview and observation were used in collecting the needed data at selected craft centres in the Kwabre East District, Ejisu-Juaben municipality, Kumasi sub-metro and metropolitan in the Ashanti region of Ghana. The study employed both descriptive and experimental research methods based on the qualitative research approach. It was revealed that Kente and Adinkra enjoy wide reputation and therefore are considered as prestigious clothes. However, Nwomu cloth does not have this fame, only indigenes understand its usage and the philosophy behind its production. In view of this, it is recommended that the elders who are endowed with this unique craft must open their doors to the youth to learn the craft.
\end{abstract}

Keywords: Nwomu cloth, hand-made, embroidery, Asantes, satin stitch

\section{Introduction}

Asante, as an ethnic group, has various decorative styles and techniques of enhancing their textile products. One of such decorative styles is the traditional hand-made embroidery commonly known as Nwomu. Nwomu is characterized by vertical stripes of coloured yarns stitched in sections along the lengthwise direction of the cloth done basically in a plain Kente cloth which enhances its aesthetic appeal. Nwomu as decorative embroidery technique employs the use of varied satin stitch used to complement the beauty of Adinkra cloth-a stamped cloth that was originally done with natural dyes extracted from the bark of Badie tree (Awuyah, 2012). Adinkra cloth was originally produced for the royal Asantehene and his sub-chiefs. The most elaborate designs of the cloths were purposely for the Asantehene. Adinkra cloth is used during funerals and other festive occasions with the prior aim of bidding farewell to a beloved one (Ofori-Ansa, n.d.). Today, other fabric types can also be hand embroidered with the Nwomu technique without printing the Adinkra symbols or designs in them. This fabric is known as Nwomuntama (Nwomu cloth).

Historical accounts revealed that the art of Nwomu amongst the Asantes was practiced by the indigenes long before the emergence of the Adinkra cloth (Awuyah, 2012). The prestigious clothes found among the Asantes are Kente and Adinkra. People travel far and near to observe the craft and its accessories and even purchase pieces as souvenirs. Nwomuntama on the other hand does not have much reputation. Only indigenes know and understand its usage and philosophy. Nwomu is an Akan language which literally means "piercing through something". Nwomu involves sewing with needle as a means of joining two pieces of fabrics in a

Emmanuel Kodwo Amissah, Ph.D., Department of Art Education, School of Creative Arts, University of Education. Bernard Asumeng Amoako, M.A., SDA Senior High School.

Osuanyi Quaicoo Essel, M.Phil., Department of Art Education, School of Creative Arts. University of Education. 
decorative style, and creating interesting designs in a fabric or at the selvedge. Nwomu cloth has been used and worn by various prominent people in Ghana since time immemorial but its exact origin is unknown. Many have learnt this craft at various craft centres in the Ashanti Region without knowing much about its evolution and history.

\section{Purpose of the Study}

The study sought to delve into this awesome craft to investigate the historical background of the traditional hand-made embroidery technique. It is also aimed at identifying and describing how this traditional hand embroidery is executed, what tools, materials, and changing trends it has undergone through the ages.

\section{Research Questions}

What is the historical background of the traditional hand embroidery technique?

How is the traditional hand-made embroidery executed, and what are the changing trends?

Can any other decorative artefacts be made with this hand-made embroidery technique?

\section{Methodology}

The research design adopted for the study was mixed method—using the descriptive research tool under qualitative approach, and design-based research. The descriptive method was used to provide accurate description of tools, materials, and processes involved in the production of the Nwomu cloth. This helped in the narration of relevant information on the historical background of the craft and the changing trends. Interview was restricted to experts endowed in Nwomu cloth design.

\section{Data Collection Instruments}

The study made use of interview and observation as the main data collection instruments. According to Leedy and Ormod (2005) in qualitative studies there is the need to acquire data from varied sources for the purpose of triangulation. The unstructured face-to-face interview with the respondents was recorded on audio-tape. In observing the respondents both participant and non-participant observations were used by the researchers.

\section{Population}

The population for the study was selected purposively from the following townships: Ntonso, Bonwire, Ahinsan, Ashtown (Manhyia Palace) and Centre for National Culture (Traditional Weaving Section), and Bantama-Kumasi all of the Ashanti Region of Ghana. The target groups were the traditional weavers, machine embroiders, sellers of Nwomu cloths, curators at museums and galleries, chiefs, elders, historians of Nwomu cloth (Adinkra cloth). They were further grouped into three categories:

Category 1: Weavers, experts and specialists in the Nwomu craft;

Category 2: Sellers and curators at Nwomu shops, museums and galleries;

Category 3: Users of Nwomu cloth (chiefs, elders and general public who are endowed with the necessary knowledge on the Nwomu craft).

\section{Sample and Sampling Technique}

Frankel and Wallen (1996) define sample as a group in a research study on which information is obtained. The purposive sampling method was used to select the appropriate respondents from the main population for 
the study. This method of data collection was appropriate because there was a predestined group in mind. The individuals whom the researchers considered to have in-depth knowledge and other resources useful to the research were contacted. Thus, the sample size was determined. In all, hundred (100) individuals were identified but the researchers, however, obtained access to only 40 who were consequently interviewed.

\section{Data Collection Procedure}

Interview. This is an oral presentation of obtaining information from respondents. Frankel and Wallen (1996) define interview as the careful asking of relevant question(s) pertaining to a particular problem. The respondents gave vivid description in narrating the needed information while the researchers had the opportunity to clarify issues and statements made by the respondents. The table below indicates the categories of respondents who were interviewed (see Table 1).

Table 1

Categories of Respondents Interviewed

\begin{tabular}{lll}
\hline Respondents number percentage (\%) & & 42.5 \\
Category 1: Weavers, experts and specialist of Nwomu craft & 17 & 22.5 \\
Category 2: Sellers and curators at Nwomu shops, museums and galleries & 9 & 35 \\
Category 3: Users of Nwomu cloth (Chiefs, elders and general public) & 14 & 100 \\
Total & 40 & \\
\hline
\end{tabular}

Observation. The researchers witnessed series of activities done by the weavers and embroiders at the traditional weaving section of the Centre for National Culture, Kumasi. Bonwire and Ntonso were also involved in the production of Nwomu cloths. Both participant and non-participant observations were used by the researchers. Apart from the interviews and observations, taking of pictures and recording of data were employed to get first-hand information from the respondents.

\section{Data Analysis Plan}

Data collected by the researchers during the interview and observation were analyzed based on the purpose of the study.

\section{Results and Discussion}

The discussion of the results has been presented sequentially in addressing the research questions and grouped to reflect the topical issues identified in the study.

\section{History and Origin of Nwomu}

It is believed that Nwomu was practiced by the indigenes long before the emergence of Adinkra in the 17th century. It is said that, after the Asantes defeated Nana Kofi Adinkra and the people of Gyaman in 1818, they brought along their weavers and craftsmen to Kumasi (Ghana) to be slaves to Asante King, Nana Bonsu-Panyin (Willis, 1998; as cited in Essel \& Opoku-Mensah, 2014). These craftsmen started to design some of their clothes and other articles for the Asante King and his royals at Ahinsan. These artworks and designs included Nana Kofi Adinkra's symbols. In investigating some historical aspect of Ghana's ethnic art, Essel and Opoku-Mensah (2014, p. 32) conclude that "symbol creation, fabric construction and decoration techniques such as adinkra printing is, perhaps, an enculturated Egyptian experience refined and practiced in Ghana and possibly not a nineteenth century art”. Adding to that Anene and Brown (1968) say the major ethnic groups in Ghana had settled by the 10th century. This helps in establishing that they migrated with the craft to present day Ghana. 
Adinkra clothes made for the chiefs and the royals, with time began to fade so the craftsmen thought of reviving the cloth. They dyed and stamped the Adinkra symbols again into the cloth. But this time the cloth would not look like the previous ones. They cut into pieces and joined them with Nwomu style. This revived cloth was used for attending funeral. Conventional colours the early embroiders started with were black, red, and white. Consequently, the early designs woven employed black and white, red and black with dominant background colours of black or red respectively; hence the names Kobene (Red) and Kuntunkuni (black). Large and small pieces of Adinkra clothes were joined by knots or stitched with cotton thread and needle. This was in existence until one weaver called Appau, son of Gyamanhene brought from Ahinsan used dyed colourful cotton wool to make the first Nwomu cloth known as Asanteman. The Asanteman is a replica of the Kente cloth known as Oyokoman. It has the same colour combination pattern of yellow, green, and black. Again, it has the same philosophy and usage because it was used by the royals which include the Oyoko clan.

The pioneer weavers obtained strands from plant fibres which were processed for weaving. There were no colourful threads in the olden days. One of the commonly used plant fibres was cotton which was processed, dyed in different colours and spun into yarns. Three men who were acclaimed the first Adinkra and Nwomu makers in Ntonso were elders Kwaku Nsia, Pinkyehen and Kwadwo Appiah. They made the dye in small vats in which they dipped carved Adinkra motifs fashioned from cocoyam and cassava to stamp the cloth. Kwadwo Anane, who died five decades ago, was the first calabash stamp carver in Ntonso. Originally, the cloth to be used for printing was hand woven with hand-spun thread woven on a Kente-style loom. At first, the cloth was dyed with mud. Kuntunkuni (Black) and Kobene (Red) natural dyes were introduced later.

\section{Tools, Materials and Equipment}

The following are some of the tools and materials that are used by the weavers: assorted yarns, set of needles, skeiner or winder, stretching poles, trimming knife, pair of scissors, tensioning cords (nhyetire/Tabono), fabric, tape measure, sewing or embroidery machine.

\section{Types of Existing Nwomu Designs}

Basically, Nwomu designs are categorized into two main groups: Kukrubuo (the linear design) and Kawo (the centipede or intricate design). The most common Kukrubuo designs today are Asanteman, Sikafutro, Aburo ne Nkatie, Hausa Nkyerew, Black and White (see Figures 1 and 12), Otumfuo, Nwotua, and Dwenimmen. These are characterized by vertical running stitching with variations in yarn combinations and arrangements (see Figure 1).

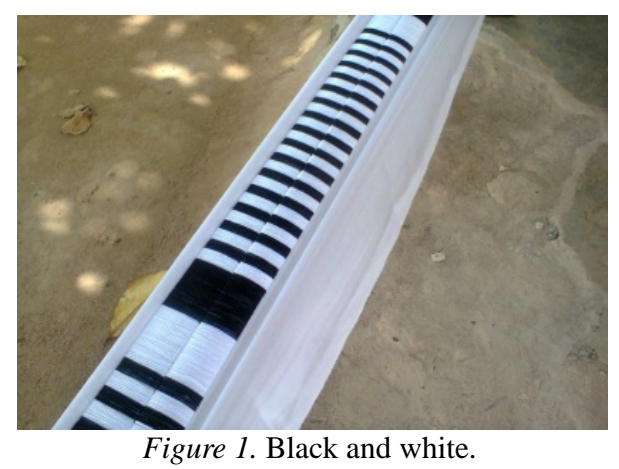

Kawo on the other hand are vertical stitching techniques with irregular or serrated edges. Some are also characterized by shapes which may look like Kente patterns or stairs. These alternating irregular edges symbolize the legs of a centipede or millipede hence the name Kawo (see Figure 2). 


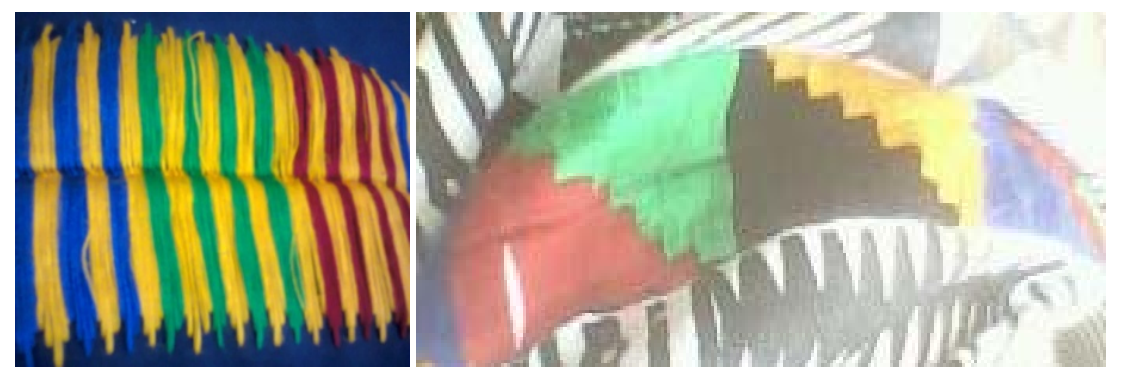

Figure 2. Kawo style in Kente pattern.

\section{Naming Nwomu Design}

Names are very symbolic and significant in every Ghanaian community. Easy identification and description can be made of a person or product when there is a specific name given to him or it. In naming clothes produced with the Nwomu technique, the colour(s) of yarns, the design and strip combinations, the background colour of the fabric, and the Adinkra motif designs that characterized the cloth are considered.

\section{Production of Nwomu Cloth}

There are three main processes or procedures involved in the production of Nwomu cloth. The following are the stages the researchers observed during an execution of different kinds of Nwomu cloth: Yarn Preparation, Fabric Preparation, and Weaving Process.

\section{Yarn Preparation}

Conversion of yarns from cones into hanks. Yarns on cones are unwound from the skeiner. They are then removed from the skeiner and cut into pieces of about $50 \mathrm{~cm}$ long and converted into hanks (see Figure 3).

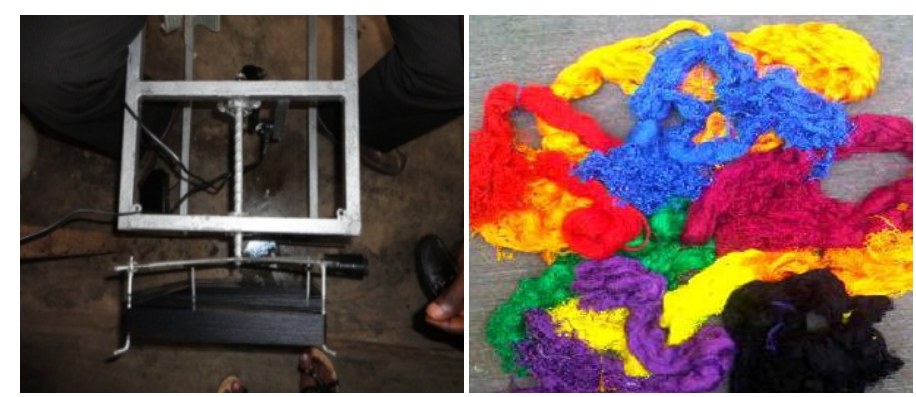

Figure 3. Mechanical skeiner used to convert yarns into hanks.

Knotting the yarns. The next process is the knotting of yarns. This involves plying individual yarns of four at the extreme end of the yarns. This is done to avoid entangling and wastage of yarns (see Figure 4).

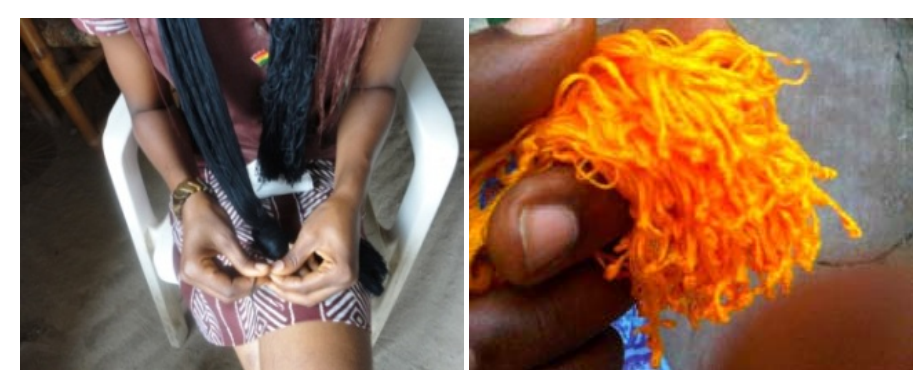

Figure 4. Knotting the yarns. 


\section{Fabric Preparation}

Preparation of fabric for weaving. The fabric to be stitched is measured and cut into pieces preferably 18 inches wide and 108 inches long with scissors. Two pieces of the cut out fabric are picked and folded inward about $2 \mathrm{~cm}$ and temporarily sewn together at extreme ends (see Figure 5).

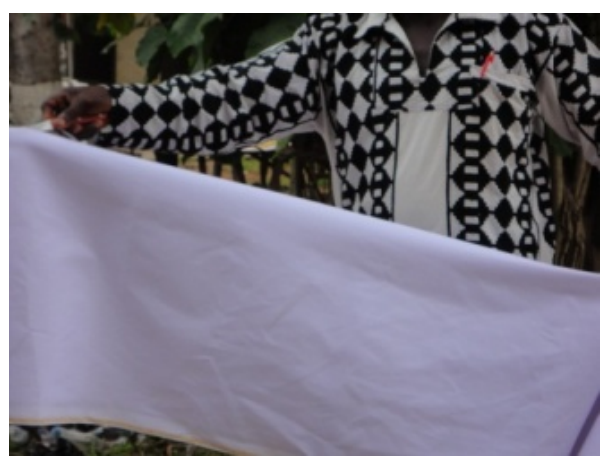

Figure 5. A weaver cutting a fabric.

Preparation of "Nhyetire". The purpose of the Nhyetire (holder) is to secure and hold the fabric firmly when stitching. The Nhyetire also maintains the tension in the fabric at all times. A piece of bamboo stick is placed in the fabrics to be used and sewn together. This is to strengthen the Nhyetire and prevent it from moving easily (see Figure 6).
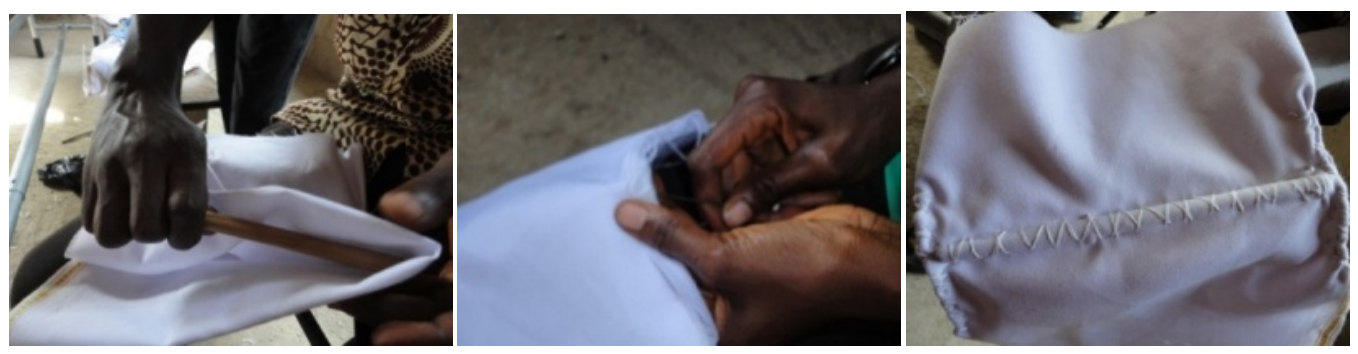

Figure 6. Preparation of Nhyetire.

Fixing the "Nhyetire" to the strip to be stitched. This process includes the attachment of the "Nhyetire" to the strip to be woven which had already been tied together by the weaver. This is done by aligning the right sides of the strips and the holder together. Both ends of the folded strips are secured and stitched to the Nhyetire using the stem stitching technique (see Figure 7).

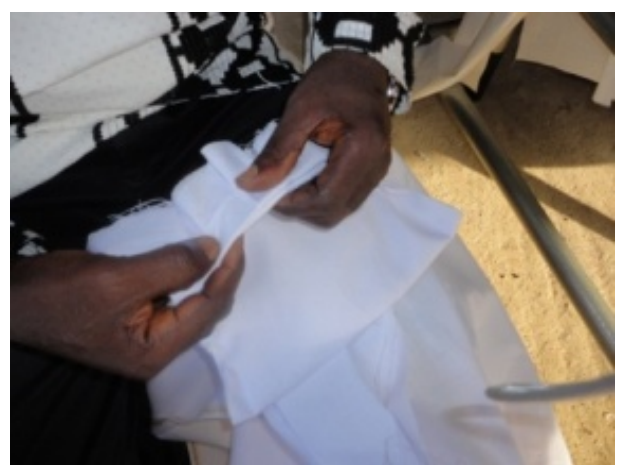

Figure 7. Fixing the Nhyetire to the fabric. 
Tensioning and aligning folds on the strip. The fabric or strip to be woven is tensioned and tied to the poles or to a hook (see Figure 8). The next step is the preparation of the strip for stitching. This is done by first securing, aligning, and tacking the folds with needles (see Figure 9). Several needles are used to secure the folds together.

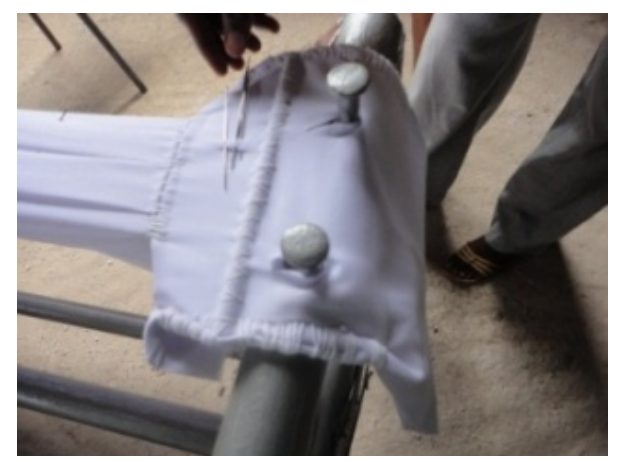

Figure 8. Nhyetire tied to a hook.

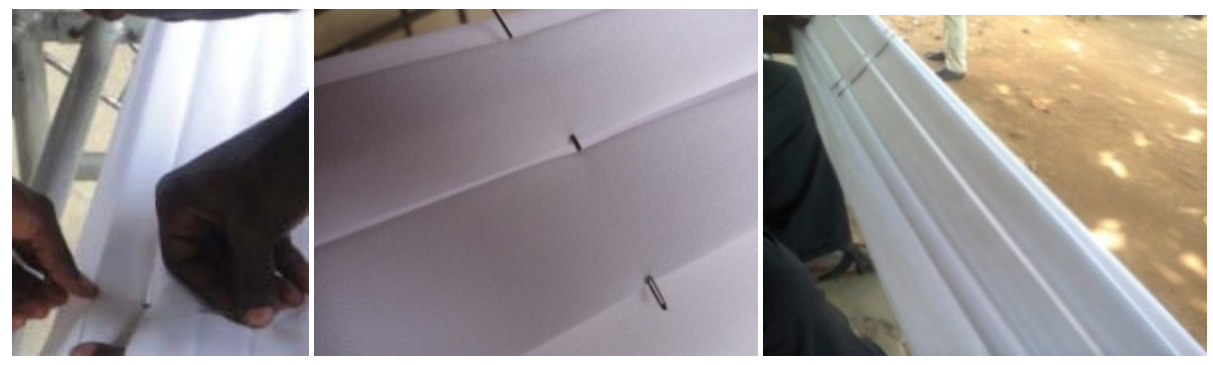

Figure 9. Folds secured with needles.

\section{Weaving Process}

Threading the needle. When using ply yarns, it is difficult to pass the end of the yarns through the eye of the needle. This is because the yarns are plied in fours and difficult to thread it through the eye of a needle since the eye of the needle is too small. In order to achieve a successful threading process, use corresponding needle size and type.

Actual stitching process (Nwomu stitching). The length of the fabric is measured to ascertain the number of design repeats that will fit into the length of the strip. If there are images or shapes in the design, it is first drawn (or traced) onto the fabric before stitching. There are many stitching styles that can be used in embroidery today but with this indigenous hand embroidery, running stitches is used. The embroidery is done by piercing the threaded needle through the fabric exactly at the edge of the folds, that is, where the folded end comes into contact with the surface of the strip beneath the folds. The needle is then pulled out through the opening where the other ends of the folded edges meet (this can be seen as an imaginary line between the folded ends as in Figure 10). The threaded needle is finally pierced through the opposite side where the folding of the other strip ends, and then reversed to its original stitching end. This process is continued in similar fashion until the thread on the needle is exhausted. This technique is repeated until the entire length of the strip is completed. A schematic drawing of the stitching process (that is, the use of vertical cross stitch) is shown at Figure 10 and Figure 11 (Awuyah, 2012). Figure 12 gives a realistic view of the how the sewing appears on the fabric. 

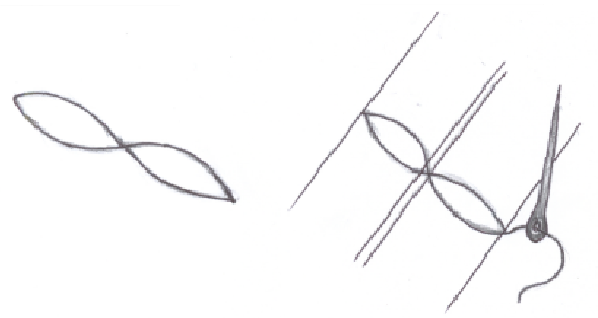

Figure 10. Cross section of the stitching process.

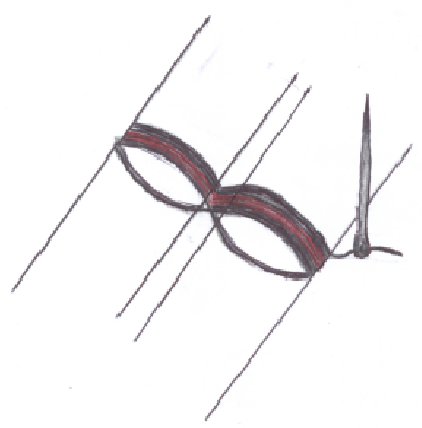

Figure 11. Schematic arrangement of the yarns when stitching.

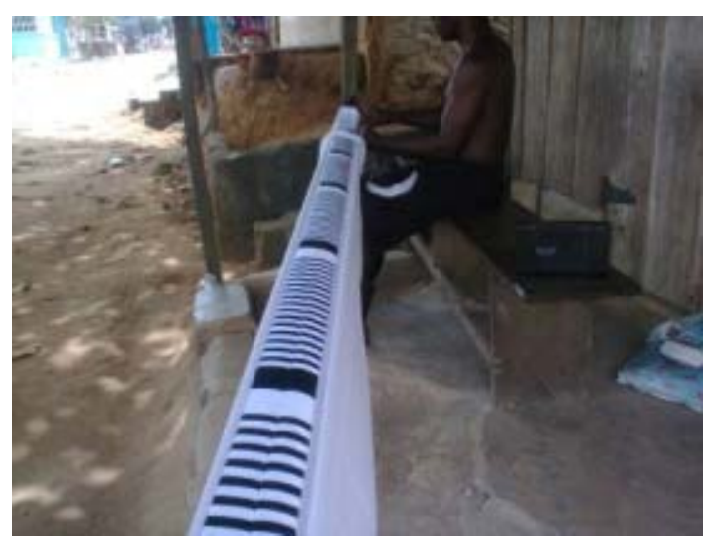

Figure 12. A weaver weaving the Black and White.

After stitching, the embroidered strip was then separated from the holders with the help of the trimming knife. This process was applied to all the strips. If the fabric to be woven is meant for a relatively bigger cloth, five pairs of woven strips are used.

Sewing the end of strips together. The individual strips are joined together by stitching, and folded at the ends where they accommodated the Nhyetire. To cover the ends of the cloth and avoid fraying of the fabric, it is sewn with the help of a sewing machine.

\section{Changing Trends of Nwomu in the Modern 21st Century}

Nwomu stitching technique has welcomed the emergence of appliqué and embroidery combinations, whereby the electric machine or equipment is used to create intricate designs unto the Nwomu cloth (see Figure 13). 


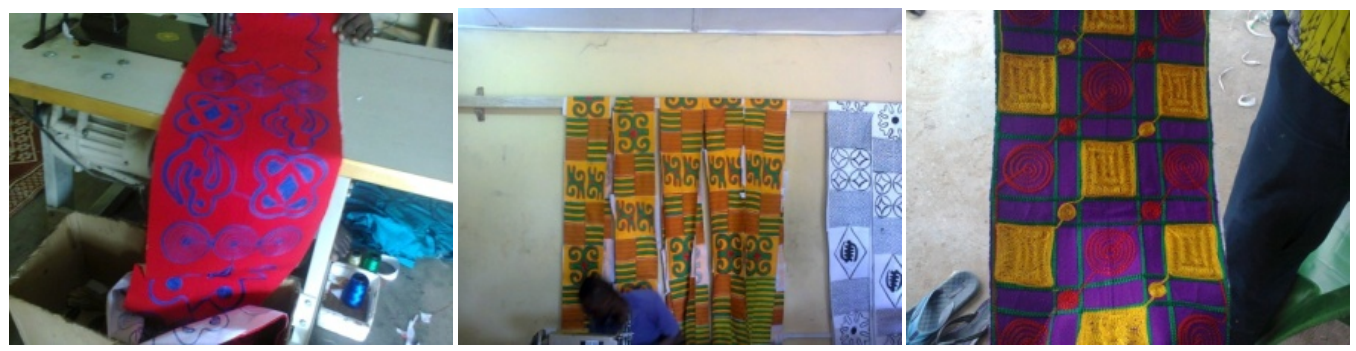

Figure 13. Appliqué embroideries by an electric machine.

Heat transfer technique and computerised equipment for superb printing as a way of designing to add a good visual appeal to fabrics has also influenced Nwomu designs. Computers have added another twist into the stitching technique making the process easier for mass production of embroidered designs. The computerized machine has brought another technique of cloth designing known as Obama (see Figure 14). During President Obama's visit to Ghana, a special Nwomu cloth design composed of a combination of appliquéd embroidery and Ntaremu was presented to him as a gift, hence, the name of the cloth design, Obama.

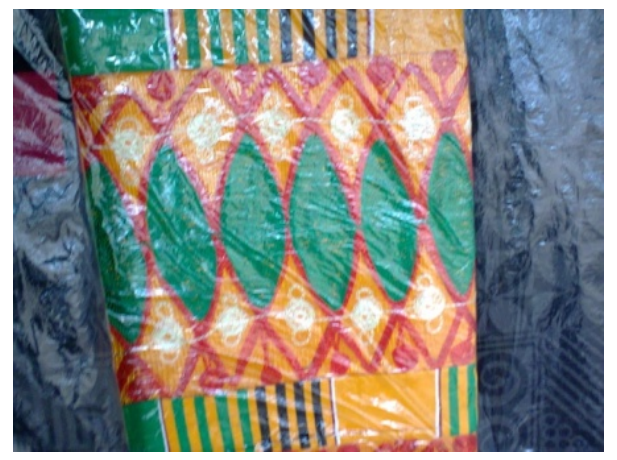

Figure 14. Obama.

Another changing trend is the advent of Ntaremu technique (see Figure 15). Ntaremu is a modern way of incorporating the unique Nwomu technique in the form of woven Kente strip into a cloth. With this technique, the fabric is marked out into sections depending upon its size and the ntaremu design fixed between these sections with the help of hand needles. Using the ntaremu technique makes it easier to work with fabrics originally made with plastic or metallic ornamentations which may pose problem in piercing them with hand needle; and seals the opened gaps associated with lacy fabrics. Besides, ntaremu required the use of less time and energy in its production in comparison to nwomu. It is also less costly.

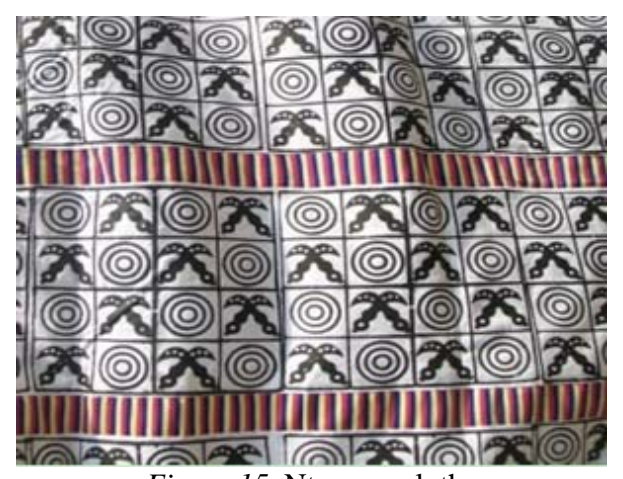

Figure 15. Ntaremu cloth. 
In addition to the techniques of joining the strips, is the creation of sophisticated Kawo designs. These designs are hand woven with Kente patterns (see Figure 16), Adinkra symbols (see Figure 17), totems or brass symbols (see Figure 18) and even alphabets or names of organizations and institutions (see Figures 19 and 20).

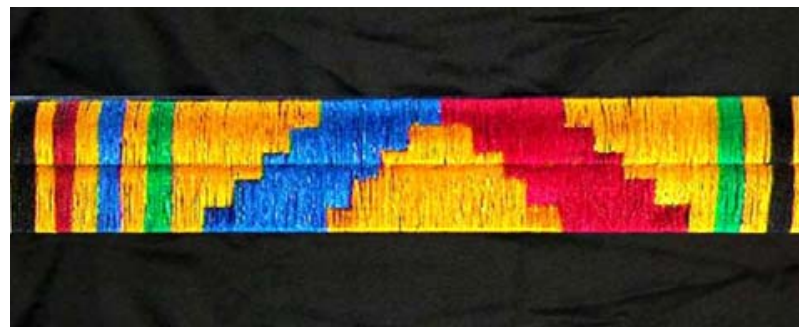

Figure 16. Kente pattern.
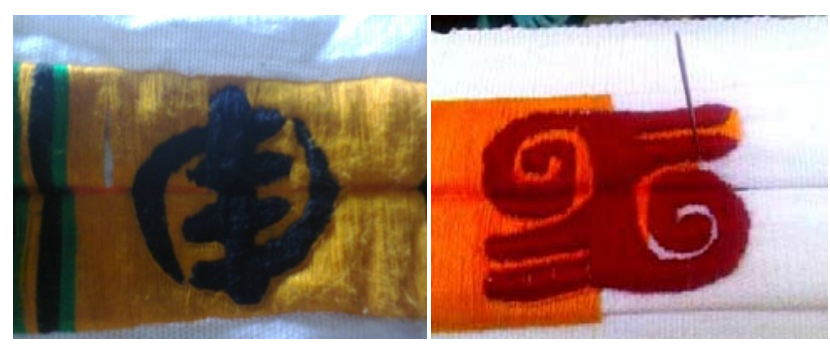

Figure 17. Adinkra symbols.

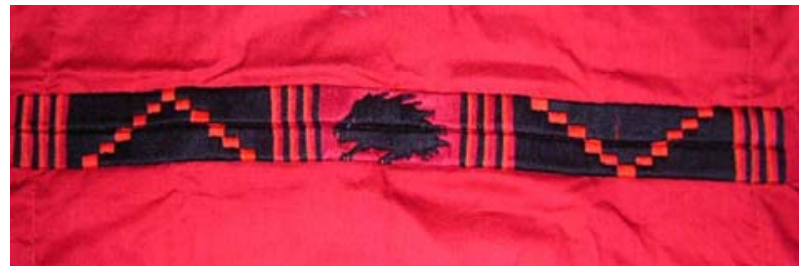

Figure 18. Kotoko (Porcupine).

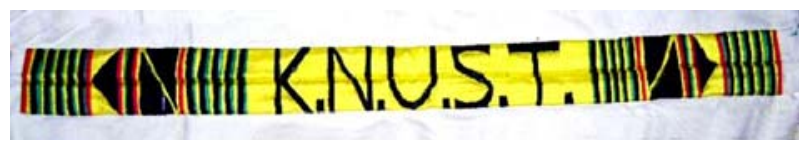

Figure 19. KNUST.

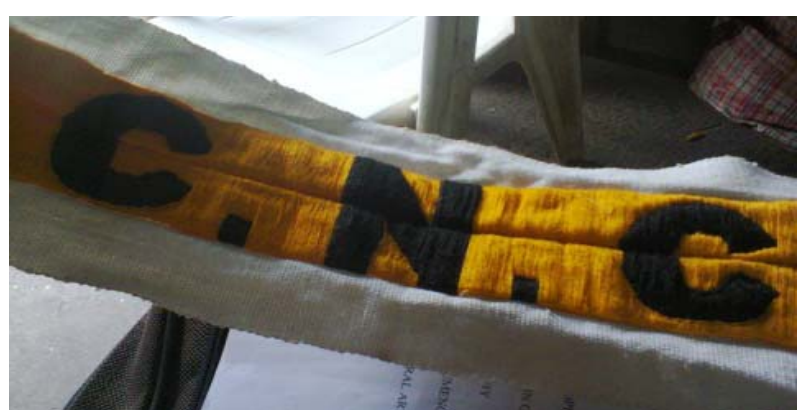

Figure 20. C.N.C.

Researchers have manufactured Nwomu machine or equipment with galvanized pipes (see Figure 21) which has rollers to accommodate woven fabrics. They were motivated to do this when they observed that the traditional stretching poles have no rollers. Fabrics woven on the poles by the weavers are placed on a mat, dirtying the cloth in the event. This Nwomu machine differs from the traditional ones and even works better. 


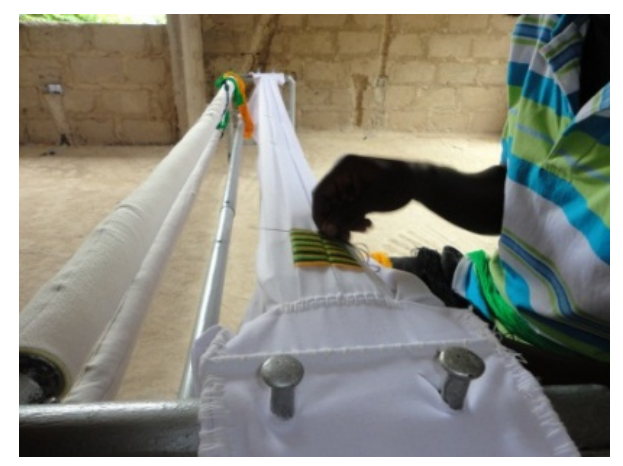

Figure 21. Nwomu machine.

\section{Using the Kukrubuo Techniques to Manufacture Decorative Artefacts}

The traditional weavers have conservative thoughts and misconceptions that apart from the designs being used for cloth production and the product worn as men or women's cloth, the Kukrubuo technique could not be used for any other decorative article or artefact. This compelled the researchers to investigate and experiment to find out if some of the Kukrubuo designs could be used to make decorative artefacts such as pillowcases, chair backs, arm rests, and wall hangings. These artefacts are meant to decorate living rooms and offices. The ideas were based on the previous knowledge of the techniques and uses of Nwomu designs and the results was that these designs could be used for other decorative artefacts such as chair backs and pillowcases (see Figure 22).
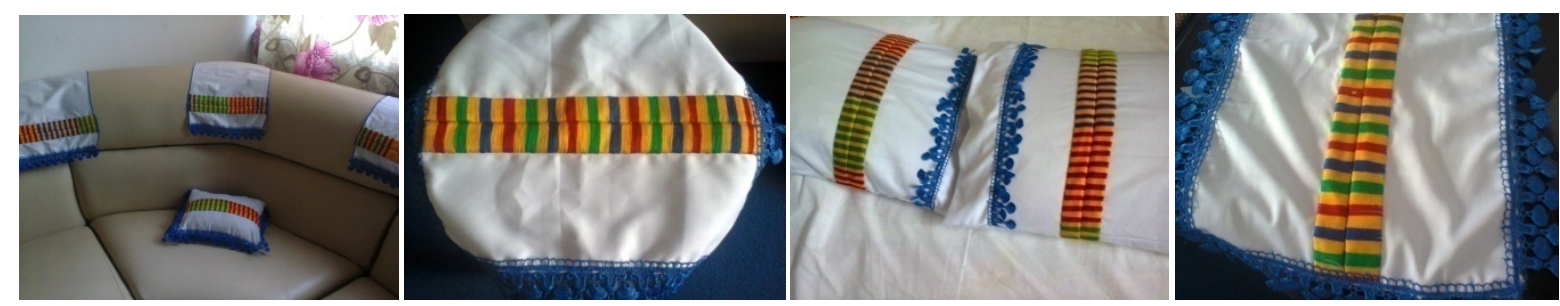

Figure 22. Decorative artefacts made for rooms.

\section{Conclusion}

Though Nwomu predates Adinkra fabric production in Asanteland, many people including the weavers in the craft have little or no knowledge of its origin. Historical accounts revealed that the art of Nwomu amongst the Asantes was practiced by the indigenes long before the emergence of the Adinkra cloth. It became prominent with the introduction of Adinkra cloth some centuries ago. The most prestigious clothes found among the Asantes are Kente and Adinkra. People travel far and near to observe the crafts and their accessories and even purchase pieces of these unique clothes. Nwomu on the other hand does not have much fame. Its usage and philosophy seemed to be limited to the indigenes.

There are types of Nwomu designs namely kukrubuo and kawo. Kukrubuo designs are characterized by vertical running stitching with variations in yarn combinations and arrangements. Kawo on the other hand are vertical stitching techniques with irregular or serrated edges. Some are also characterized by shapes which mimic Kente patterns or stairs-like designs. These alternating irregular edges symbolize the legs of a centipede or millipede hence the name Kawo. It has evolved and adapted modern embroidery equipment that intensifies creation of intricate designs and making the craft less laborious. Hitherto the study, the Nwomu embroiderers at 
the craft centres had not exploited with using the technique to produce other decorative artefact such as pillowcases and chair backs apart from its conventional usage in moderately large pieces of clothes worn for occasions. The researchers attempted to produce chair backs and pillowcases using the Nwomu technique which proved useful. The study has exposed the step by step method of producing Nwomu cloth. It recommends automation of the process to increase production.

\section{References}

Adams, L. S. (1999). Art across time (Vol. 1). New York: McGraw-Hill Publisher.

Adonteng, Y. E. (2009). Kwahu cultural values: Their impact on the people’s art (Unpublished Master thesis, Kwame Nkrumah University of Science and Technology, Kumasi, Ghana).

Anene, J., \& Brown, G. (Ed.). (1966). Africa in the nineteenth and twentieth centuries. Nigeria: Ibadan University Press.

Arthur, G. F. K., \& Rowe, R. (2001). Akan Kente cloths and motifs (Akans cultural symbols project. Marshall University).

Appiah, K. A. (1993). In my father's house: Africa in the philosophy of culture. New York: Oxford University Press.

Awuyah, I. K. (2012). Exploiting techniques in Asante indigenous hand embroidery for Adinkra cloth production. Kumasi: Kwame Nkrumah University of Science and Technology.

Essel, O. Q., \& Opoku-Mensah, I. (2014). Pan-African artistic reflections in Kwame Nkrumah Memorial Park. International Journal of African Society Cultures and Traditions, 1(2), 30-41.

Frankel, J. R., \& Wallen, N. E. (1996). How to design and evaluate research in education (3rd ed.). New York: McGraw-Hill Inc. Leedy, P. D., \& Ormod, E. J. (2005). Practical research: Planning and design (8th ed.). New Jersey: Pearson Education, Inc. Ofori-Ansa, K. (n.d.). Ashanti Kente cloth-More than a piece of fabric. Retrieved from http:// Kenten.midwesttradegroup.com Opoku, J. Y. (2005). A short guide to research writing in social sciences and education (2nd ed.). Accra: Ghana Universities Press. 